\title{
Effects of Penicillium chrysogenum var. halophenolicum on kraft lignin: color stabilization and cytotoxicity evaluation
}

\author{
Marlene Remédios ${ }^{1}$ - Filomena A. Carvalho ${ }^{2}$ Francisco J. Enguita ${ }^{2}$. \\ Carlos Cardoso $^{3}$ - Ivo C. Martins ${ }^{2}$ - Nuno C. Santos ${ }^{2} \cdot$ Ana Lúcia Leitão ${ }^{1}$
}

Received: 11 November 2015/Accepted: 21 March 2016/Published online: 13 April 2016

(c) The Author(s) 2016. This article is published with open access at Springerlink.com

\begin{abstract}
Wood industries and agricultural crops generate an inexhaustible supply of by-products like lignin, which constitutes an environmental problem. Increasing efforts have been done to find new applications for lignin. One of them is as a food additive, but its chemical nature makes it sensitive to browning which constitutes a major drawback for this type of lignin application. In the present study we are documenting how color stabilization of a commercial kraft lignin was achieved after the treatment with Penicillium chrysogenum var. halophenolicum. In addition the fungal capacity to remove lignin is studied together with the effect of its treatment on cytotoxicity of lignin. P. chrysogenum var. halophenolicum was able to transform lignin, ensuring its color stability for more than 24 months. Dynamic light scattering and atomic force microscopy showed that the fungus contributed to homogenize particle size and hydrodynamic properties in lignin suspensions without increase the toxicity over HeLa cells and human primary fibroblasts. These findings suggest new uses for kraft lignin after $P$. chrysogenum var.
\end{abstract}

Ana Lúcia Leitão

aldl@fct.unl.pt

1 Departamento de Ciências e Tecnologia da Biomassa, Faculdade de Ciências e Tecnologia, Universidade NOVA de Lisboa, Quinta da Torre, Campus de Caparica, 2829-516 Caparica, Portugal

2 Instituto de Medicina Molecular, Faculdade de Medicina, Universidade de Lisboa, Av. Prof. Egas Moniz, 1649-028 Lisbon, Portugal

3 Instituto Nacional do Mar e Atmosfera, Unidade de Valorização dos Produtos da Pesca da Aquicultura, L-IPIMAR, IP-INRB, Av. Brasília, 1449-006 Lisbon, Portugal halophenolicum treatment providing an effective approach for improve color stability.

Keywords Penicillium chrysogenum var. halophenolicum · Color · Lignin removal · Toxicity · Transformation

\section{Introduction}

Lignin is the second most abundant natural product of vegetal origin, conferring impermeability and structural support to plants (Baurhoo et al. 2008; Pérez and Moraleda-Muñoz 2011). Its high-molecular weight structure is generally achieved by dehydrogenative polymerization of three primary hydroxycinnamyl alcohols (monolignols): coniferyl alcohol (guaiacyl propanol, G), coumaryl alcohol ( $p$-hydroxyphenyl propanol, H), and sinapyl alcohol (syringyl propanol, S), being classified as a three-dimensional amorphous polymer. As a major component of lignocellulosic material, lignin is found in wastes that are produced in large amounts by many industries including forestry, agriculture and food. Global wood consumption is around $3.5 \times 10^{9} \mathrm{~m}^{3} /$ year, being broadly applied for pulp and paper products, production of fuel and building materials (Martinez et al. 2005). This huge production generates a large amount of by-products with negative impacts to the aquatic, and consequently to the terrestrial ecosystem. The adverse effect is due not only to the organic load and toxicity of effluents, but also to the esthetically unacceptable color of water bodies largely due to lignin and its derivatives. The brownish dark coloration of water bodies could be the result of enzymatic activities over aromatic compounds present in lignocellulose-derived materials. Among them, polyphenol oxidases catalyze the oxidation 
of ortho-dihydroxyl phenols in the presence of molecular oxygen to the corresponding ortho-quinones, which spontaneously polymerize to produce dark or brown pigments (Walker 1977).

One of current challenges faced by a more environmental-friendly science and industry is to employ natural resources and waste products maximizing economic performance. Indeed, new uses for lignin as fuel, biomaterials, biocides, biostabilisers, crop cultivations and animal feed is now a reality (Lora and Glasser 2002). Moreover, it was suggested that purified lignins may also bring new health benefits to animals (Baurhoo et al. 2008). However, the color stability of lignin products constitutes a major drawback for its general use as additive. In this context, the color preservation of food products during processing and storage is one of the main challenges of food industry; since their organoleptic properties are an important requisite that contributes decisively to food acceptance, based on the initial perception of food condition and degree of processing, among other characteristics (Lopez-Nicolas and Garcia-Carmona 2007).

Due to its aromatic nature and structural complexity, lignin is resistant to the attack of the majority of microorganisms (Baurhoo et al. 2008; Pérez and Moraleda-Muñoz 2011). Indeed, in nature, white-rot fungi are the only efficient lignin degraders, since they have the ability to completely mineralize this polymer, and consequently they are quite important in the global turnover of carbon from woody plants (Wong 2009). The best studied are Phanerochaete chrysosporium, Pleorotus ostreatus, Bjerkandera adusta, Pycnosporus cinnabarinus, Ceriporiopsis subvermispora, Phlebia sp., or Trametes versicolor (Pérez and MoraledaMuñoz 2011). Meanwhile, there are other fungi that have the ability to partially degrade lignin. For instance, a Penicillium chrysogenum strain was able of using kraft, organosolv, and synthetic dehydrogenative polymerised lignins with low degradation rates (Rodriguez et al. 1994). Despite of that, only a few reports have discussed lignin degradation by Penicillium strains (Polman et al. 1994; Rodriguez et al. 1994; Hao et al. 2006; Yadav and Yadav 2006; Dwivedi et al. 2011); however, as far as we know kraft lignin removal and color stabilization by imperfect fungi has not yet been described. We have previously characterized a halotolerant $P$. chrysogenum strain, $P$. chrysogenum var. halophenolicum, isolated from a salt mine (Leitão et al. 2012), and able to metabolize phenolic compounds under osmotic stress (Leitão et al. 2007; Guedes et al. 2011).

In the present work, we aimed to study the effect of $P$. chrysogenum var. halophenolicum on kraft lignin transformation and color stability, investigating if this strain has the potential to become a browning control agent, to impart lignin with stable color that may promote its use as an additive for biotechnological applications.

\section{Materials and methods}

\section{Strain and culture conditions}

P. chrysogenum var. halophenolicum was used throughout this study; this strain was isolated from a salt mine in Algarve, Portugal, and previously characterized (Leitão et al. 2012).

P. chrysogenum var. halophenolicum was maintained at $4{ }^{\circ} \mathrm{C}$ on nutrient agar plates (Difco, BD diagnostic systems, Hunt Valley, MB, USA) with $2 \%$ (w/v) NaCl. Pre-cultures of cells were routinely aerobically cultivated $(160 \mathrm{rpm}$ in a Certomat $^{\circledR}$ BS-T Incubator, Sartorius stedim biotech, Goettingen, Germany) at $25 \pm 1{ }^{\circ} \mathrm{C}$ in $100 \mathrm{~mL}$ of complex medium (MC: glucose, $30.0 \mathrm{~g} / \mathrm{L} ; \mathrm{NaNO}_{3}, 3.0 \mathrm{~g} / \mathrm{L} ; \mathrm{MgSO}_{4}$ $7 \mathrm{H}_{2} \mathrm{O}, 0.5 \mathrm{~g} / \mathrm{L} ; \mathrm{NH}_{4} \mathrm{Fe}\left(\mathrm{SO}_{4}\right)_{2} \cdot 12 \mathrm{H}_{2} \mathrm{O}, 10.0 \mathrm{mg} / \mathrm{L} ; \mathrm{K}_{2} \mathrm{HPO}_{4}$, $1.0 \mathrm{~g} / \mathrm{L}$; yeast extract, $5.0 \mathrm{~g} / \mathrm{L} ; \mathrm{NaCl}, 20.0 \mathrm{~g} / \mathrm{L} ; \mathrm{pH} 5.6)$.

To investigate the ability to transform kraft lignin, the strain was cultivated in 500-mL flasks containing $100 \mathrm{~mL}$ of MC during $68 \mathrm{~h}$. Cells were collected by centrifugation and washed in $0.85 \%(\mathrm{w} / \mathrm{v})$ of $\mathrm{NaCl}$. A $15 \%$ of the preinoculum was inoculated in modified Janshekar medium (Janshekar et al. 1982) containing $\mathrm{NaNO}_{3}(1.00 \mathrm{~g})$ in substitution of $\mathrm{NO}_{3} \mathrm{NH}_{4}(0.496 \mathrm{~g})$ and without vitamin solution and nitrilotiacetate as a component of trace element solution and amended with $1700 \mathrm{mg} / \mathrm{L}$ kraft lignin (alkali, low sulfonate content was obtained from SigmaAldrich, St. Louis, MO, USA). P. chrysogenum var. halophenolicum was aerobically incubated $(160 \mathrm{rpm}$ in the Certomat $^{\circledR}$ BS-T Incubator) in the dark during $96 \mathrm{~h}$, at $25{ }^{\circ} \mathrm{C}$. Three replicates were used. Abiotic assays were performed in parallel with uninoculated flasks (duplicates) as negative controls.

After regular times of culture, cells were harvested and $12 \mathrm{~mL}$ of supernatant were kept frozen at $-40{ }^{\circ} \mathrm{C}$ until lignin determination assays, while approximately $12 \mathrm{~mL}$ were maintained at room temperature for lignin color stability experiments.

Microbial dry biomass was estimated gravimetrically by the method described by Gunther et al. (1995).

\section{Lignin quantification and color stability evaluation}

The commercial kraft lignin is an ideal substrate for assessing color stability and biological transformation of lignin. Firstly, the use of commercial alkali lignin avoids the concerns about chemical composition, the isolation method, or purity, since it is a commercial product. Secondly, commercial alkali lignin was employed in other studies to assess chemical effect on the structure of lignins (Kadam and Drew 1986; Suparno et al. 2005; Yuan et al. 2010; DeAngelis et al. 2011; George et al. 2011; Huang et al. 2013). 
Kraft lignin color stability experiments were conducted in a lab room fitted with a chamber temperature set at $22{ }^{\circ} \mathrm{C}$ without any special storage condition. After a time of 7, 50 days and 7 months, samples were filtered before color measurement, as described in the section of color measurement. All assays were performed in $n=3$ repetitions. The mean values and standard deviations were evaluated using analysis of variance (ANOVA).

Lignin concentrations were quantified by spectrophotometric absorption at $205 \mathrm{~nm}$ in a Spekol ${ }^{\circledR} 1500$ UV VIS Spektralphotometer (Analytic Jena AG, Germany).

\section{Atomic force microscopy}

A NanoWizard II atomic force microscope (JPK Instruments, Berlin, Germany), mounted on the top of an Axiovert 200 inverted microscope (Carl Zeiss, Jena, Germany) was used for imaging the samples. The AFM head is equipped with a $15-\mu \mathrm{m}$ z-range linearized piezoelectric scanner and an infrared laser. Samples were diluted to 1:200 in Milli-Q water and deposited on freshly cleaved muscovite mica for $20 \mathrm{~min}$. After subsequent washes, the sample was allowed to air dry at room conditions. Imaging of the samples components were performed in air tapping mode (for the 1st day fungal treated samples) and in contact mode (for the 4th day fungal treated samples). Oxidized sharpened silicon tips (ACL tips from Applied Nanostructures, CA) with a tip radius of $6 \mathrm{~nm}$, resonant frequency of about $190 \mathrm{kHz}$ and spring constant of $45 \mathrm{~N} / \mathrm{m}$ were used for the measurements. Imaging parameters were adjusted to minimize the force applied on the scanning of the topography of the samples. Scanning speed was optimized to $0.4 \mathrm{~Hz}$ (on the first day of treatment sample) and $0.8 \mathrm{~Hz}$ (on the fourth days of treatment sample), and acquisition points were $512 \times 512$ and $360 \times 360$, respectively. Imaging data were analyzed with the JPK image processing v.3 (JPK Instruments). The width and height of the samples were calculated from the cross section plots. All complex dimensions measurements were performed using the Gwyddion software (Czech Metrology Institute, Brno, Czech Republic), version 2.19.

\section{Dynamic light scattering (DLS) measurements}

Dynamic light scattering experiments were carried out at $25{ }^{\circ} \mathrm{C}$ on a Malvern Zetasizer Nano ZS (Malvern, UK), with a backscattering detection at $173^{\circ}$, equipped with a $\mathrm{He}-\mathrm{Ne}$ laser $(\lambda=632.8 \mathrm{~nm})$, using glass cuvettes with round aperture. Kraft lignin samples were diluted $1 / 10$ in MiliQ water The samples were left equilibrating for $15 \mathrm{~min}$ at $25^{\circ} \mathrm{C}$ before each measurements set (10 measurements; each one being the average of 10 runs, with $10 \mathrm{~s}$ per run). Normalized intensity autocorrelation functions were analyzed using the CONTIN method (Provencher 1982a, b), yielding a distribution of diffusion coefficients $(D)$. The measured $D\left(\mathrm{~m}^{2} / \mathrm{s}\right)$ was used for the calculation of the hydrodynamic diameter, $D_{\mathrm{H}}(\mathrm{nm})$, through the StokesEinstein relationship (Berne and Pecora 1990):

$D_{\mathrm{H}}=\frac{\kappa T}{3 \pi \eta D}$

where $\kappa$ is the Boltzmann constant $(\mathrm{J} / \mathrm{K}), T$ the absolute temperature $(\mathrm{K})$, and $\eta$ the medium viscosity ( $\mathrm{Pa} \mathrm{s}$ ). The data were statistically analyzed within each set of 10 measurements by observing the average and standard deviation, and discarding outliers. The average without outliers became close to the median in all the size points.

\section{Color measurement}

Samples color was determined using a Macbeth eye 3000 colorimeter. The color in the CIELAB system is characterized by three parameters, $L^{*}, a^{*}$ and $b^{*}$. The lightness value $\left(L^{*}\right)$, taking values from $0 \%$ (black) to $100 \%$ (white), $a^{*}$ from green $(-a)$ to red $(+a)$ and $b^{*}$ from blue $(-b)$ to yellow $(+b)$. The $L^{*}, a^{*}$ and $b^{*}$ color coordinates of each group of samples were measure after stability experiment. These values were then used to calculate the color change $\Delta E^{*}$ as a function of the stability experiment duration according to the following equations:

$$
\begin{aligned}
& \Delta L^{*}=L_{f}^{*}-L_{i}^{*} \\
& \Delta a^{*}=a_{f}^{*}-a_{i}^{*} \\
& \Delta b^{*}=b_{f}^{*}-b_{i}^{*} \\
& \Delta E^{*}=\left(\Delta L^{* 2}+\Delta a^{* 2}+\Delta b^{* 2}\right)^{1 / 2}
\end{aligned}
$$

where $\Delta L^{*}, \Delta a^{*}$ and $\Delta b^{*}$ are the changes between the initial $(i)$ and the final $(f)$ values and $\Delta E^{*}$ corresponds to a color change. The color evolution assays were performed using the measurements at time 7 days as standards, which correspond to the first measurement $(i)$ that was made after the fungal treatment, mycelia removal and storage at $22{ }^{\circ} \mathrm{C}$.

\section{Cytotoxicity evaluation}

Quantification of the toxic effects of kraft lignin and fungal treated samples at the cellular level was performed by the use of Alamar Blue ${ }^{\circledR}$ test to quantify HeLa and human primary skin fibroblasts (Coriell Instutute for Medical Research, ref. GM05565) viability (Invitrogen) using a modified version of an already described protocol (Al-Nasiry et al. 2007). Briefly, HeLa and fibroblast cells were plated in 96 well plates at $10^{5}$ cells per well in RPMI medium containing $10 \% \mathrm{FBS}$, and incubated at $37{ }^{\circ} \mathrm{C}$ and 
$5 \% \mathrm{CO}_{2}$ during at least $8 \mathrm{~h}$ to allow cell attachment to the plate surface. After this incubation time, RPMI was substituted by Opti-MEM medium to avoid serum interference with the assay. Cells were then exposed to different dilutions of the $P$. chrysogenum var. halophenolicum culture supernatants, previously buffered with $10 \times$ PBS and sterilized by filtration though $0.22 \mu \mathrm{m}$ membranes. After $48 \mathrm{~h}$, HeLa and fibroblast cells were washed twice with PBS and incubated during $1 \mathrm{~h}$ at $37{ }^{\circ} \mathrm{C}$ with Alamar Blue ${ }^{\circledR}$ following the recommendations from the manufacturer. Cell viability was quantified by determination of the fluorescence of Alamar Blue ${ }^{\circledR}$ at $590 \mathrm{~nm}$ after excitation at $530 \mathrm{~nm}$ in a fluorescence plate reader (TECAM Infinite $\mathrm{M} 200) . \mathrm{EC}_{50}$ were determined by non-linear regression using an equation for a sigmoid curve (GraphPad Prism 5.02).

\section{Results and discussion}

\section{Lignin removal}

To determine the ability of $P$. chrysogenum var. halophenolicum to remove kraft lignin, the microorganism was cultured in the presence of $1700 \mathrm{mg} / \mathrm{L}$ of commercial kraft lignin. Since no abiotic loss of lignin was detected in control samples, the decrease of lignin concentration in the presence of fungus must be due to its biological action. The growth of $P$. chrysogenum var. halophenolicum and lignin removal is depicted in Fig. 1. At the initial concentration of $1700 \mathrm{mg} / \mathrm{L}$ of kraft lignin no lag phase was observed. A lignin removal of $68.0 \%$ was achieved after $96 \mathrm{~h}$ of fungal treatment, showing a clear correlation with fungal growth. Indeed, data indicate that there were two peaks in biomass,

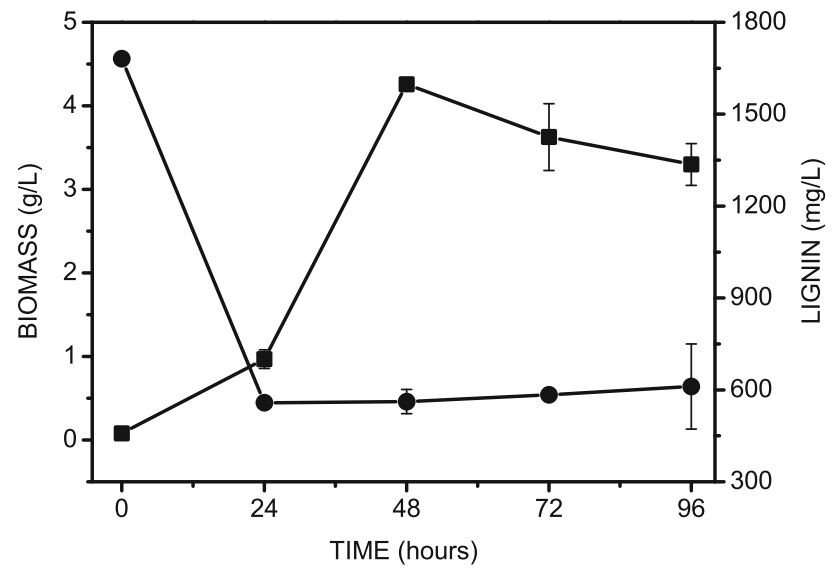

Fig. 1 Kraft lignin removal by $P$. chrysogenum var. halophenolicum during $96 \mathrm{~h}$ under aerobic conditions. Squares cell growth; circles, kraft lignin concentration. Data shown represents average of triplicates \pm standard deviations corresponding to exponential growth phase. The first one should be due to the presence of glucose in the culture media composition besides lignin, since the fungal inoculum was prepared in a complex medium with glucose, and its enzymatic system was already active and ready to use this substrate. This fact was corroborated by the absence of lag phase on fungal growth. After $24 \mathrm{~h}$ of culture, a significant increase on fungal biomass and a concomitant decrease in the lignin concentration were observed, indicating that $P$. chrysogenum var. halophenolicum growth was due to lignin transformation. In general, most of ligninolytic fungi reported require a high level of consumption of easily metabolized cosubstrate to be effective in the ligninolysis. The $P$. chrysogenum var. halophenolicum was able to remove more than $1000 \mathrm{mg} / \mathrm{L}$ of $\mathrm{kraft}$ lignin in the first $24 \mathrm{~h}$ of batch culture, which is quite interesting; whereas the heteropolymer concentration did not significantly decreased during the last three days of fungal treatment, probably due to the $\mathrm{C}-\mathrm{C}$ bonds of alkaline lignin that are highly resistant to hydrolytic breaking (Yuan et al. 2010). Kraft lignin is enriched with guaiacyl groups, where the $\mathrm{C} 5$ position in the aromatic ring represents the most abundant $\mathrm{C}-\mathrm{C}$ linkage in lignin molecules (El Mansouri et al. 2011). Fungi are the only microorganisms extensively studied for the degradation of lignin. A strain of Penicillium chrysogenum is able to degrade some synthetic and natural lignins, and mineralize $7.9 \%$ of $\left[{ }^{14} \mathrm{C}_{\beta}\right]$ DHP in 29 days (Rodriguez et al. 1996).

Recently several studies were published using commercial kraft lignin. Among them, Huang et al. reported that 500 and $700 \mathrm{mg} / \mathrm{L}$ of commercial kraft lignin is degraded by Bacillus pumilus and Bacillus atrophacus, respectively, after 18 days of incubation (Huang et al. 2013). A comparative study of natural and commercial kraft lignin degradation by Citrobacter sp. was described, showing its higher capacity to use kraft lignin than commercial kraft lignin (252 and $186 \mathrm{mg} / \mathrm{L}$, respectively) (Chandra and Bharagara 2013). Our results indicate that $P$. chrysogenum var. halophenolicum efficiently removed kraft lignin.

\section{Effect of fungal treatment on the evolution of lignin color}

To evaluate the effect of $P$. chrysogenum var. halophenolicum on lignin color, scalar parameters $\left(L^{*}, a^{*}\right.$, and $\left.b^{*}\right)$ were determined, after 7 days of storage, in samples with different times of fungal treatment. The initial $L^{*}$ value for untreated sample was 56.45. Fungal treatment did not induce any significant change in $L^{*}$ values (Table 1 ). After $96 \mathrm{~h}$ of fungal treatment the $L^{*}$ value was 56.88 , indicating that the components absorbing visible light remain constant. 
Table 1 Evolution of $L^{*}$ and $a^{*}$ and $b^{*}$ coordinates of kraft lignin samples after the absence and presence of P. chrysogenum var. halophenolicum. After treatment, fungal micelia were removed and the samples were stored at $22{ }^{\circ} \mathrm{C}$ during 7 days before color estimation $(n=3)$

\begin{tabular}{lllr}
\hline Fungal treatment $(\mathrm{h})$ & $L^{*}$ & $a^{*}$ & $b^{*}$ \\
\hline Control & $56.45 \pm 0.04 \mathrm{a}$ & $-0.81 \pm 0.03 \mathrm{a}$ & $1.87 \pm 0.03 \mathrm{a}$ \\
24 & $56.53 \pm 0.22 \mathrm{a}$ & $-0.74 \pm 0.02 \mathrm{a}$ & $2.10 \pm 0.15 \mathrm{ab}$ \\
48 & $56.82 \pm 0.02 \mathrm{~b}$ & $-0.91 \pm 0.06 \mathrm{ab}$ & $2.38 \pm 0.01 \mathrm{c}$ \\
72 & $56.64 \pm 0.10 \mathrm{a}$ & $-0.98 \pm 0.02 \mathrm{~b}$ & $2.18 \pm 0.02 \mathrm{~b}$ \\
96 & $56.88 \pm 0.05 \mathrm{~b}$ & $-0.87 \pm 0.04 \mathrm{a}$ & $2.47 \pm 0.03 \mathrm{c}$ \\
\hline
\end{tabular}

Different letters (vertically) indicate significant differences $(p<0.05)$

In the samples treated with the fungus during $24 \mathrm{~h}$ the $a^{*}$ values slightly increased, possibly due to the presence of degradation and/or oxidation products, followed by a decrease at later culture times. Nevertheless, the different times of culture led to lower values of $a^{*}$, with the initial green color still remaining after $96 \mathrm{~h}$ of treatment (Table 1). These results are compatible with chemical changes of lignin.

The $b^{*}$ values of samples increase after fungal treatment. The increase in yellowness could be caused by the low-molecular-weight phenolic compounds obtained by the action of fungal enzymes.

\section{AFM studies}

In nature, lignin is an amorphous polymeric material often associated to cellulose fibers as main constituents of plant cell walls. Since the exact structure of lignin itself is not known (Chakar and Ragauskas 2004; George et al. 2011), atomic force microscopy has been applied to characterize the topography and roughness of lignocellulosic materials in their natural forms (Chundawat et al. 2011). The AFM scanning images of lignin samples with one $(\mathrm{a}, \mathrm{b})$ and 4 days (c, d) of treatment with $P$. chrysogenum var. halophenolicum are shown on Fig. 2.

From the figure, it can be evidently noticed that fungal treatment on the lignin samples leads to morphological changes within the polymer. From air tapping mode AFM error (a) and height (b) images of the sample treated through only $24 \mathrm{~h}$, it could be seen that it is very heterogeneous in size. Opposing this, the lignin sample with $96 \mathrm{~h}$ of treatment is much more homogenous and only one size population could be visualized. To quantitatively analyze AFM height images of these populations, we measured the diameter and the height of their surface profiles (Fig. 2b, d, right images). Cross section analysis of each feature on the images was done, yielding distinct profiles. Examples of these cross sections are also shown (Fig. 2b, d, left images). The analysis indicates that the sample with $96 \mathrm{~h}$ of treatment had a unique population, with an average diameter of $321.2 \pm 53.7 \mathrm{~nm}$ and height of $28.8 \pm 8.6 \mathrm{~nm}$ $(n=11)$. We could distinguish three different populations on the lignin sample with only $24 \mathrm{~h}$ of fungal treatment, with different dimensions: $42.5 \pm 6.0 \mathrm{~nm}$ (diameter) and $5.1 \pm 1.0 \mathrm{~nm}$ (height) on population $1 \quad(n=9)$; $124.2 \pm 17.3 \mathrm{~nm}$ (diameter) and $16.8 \pm 2.7 \mathrm{~nm}$ (height) on population $2(n=16)$; and, $221.9 \pm 36.9 \mathrm{~nm}$ (diameter) and $34.8 \pm 10.9 \mathrm{~nm}$ (height) on population $3(n=23)$. There were no significant differences in the visualized roughness of both analyzed samples (Fig. $2 b$, d, right images).

From the calculated dimensions of the three populations of the $24 \mathrm{~h}$ treatment sample, we could hypothesize that populations 2 and 3 were formed by oligomers of the lignin structures of population 1 . After $96 \mathrm{~h}$ of treatment, the substantial increase in size of the lignin particles achieved on the entire population reveals the existence of polymerization or major aggregation phenomena.

\section{DLS analysis}

DLS experiments of untreated lignin and fungal treated samples are shown in Table 2. Untreated lignin showed a great variation in particle sizes and poorly resolved peaks, with three major ones observed, one corresponding, roughly, to $6-20 \mathrm{~nm}$ sized species, the other to 20-1000 nm sized species and a final one corresponding to species well over $3 \mu \mathrm{m}$. Taking only the first two (which are better resolved), the maxima of the peaks correspond to average hydrodynamic diameters $\left(D_{\mathrm{H}}\right)$ of $16.6 \mathrm{~nm}$ (scattering intensity $34.4 \%$ ) and $629.7 \mathrm{~nm}$ (scattering intensity $65.6 \%$ ). Upon 24 and $48 \mathrm{~h}$ of treatment with the fungus, the sample sizes become more uniform and overall smaller. After $24 \mathrm{~h}$ of treatment three major peaks were observed, but better resolved than in the control, since the first one corresponds mostly to, approximately, $10-20 \mathrm{~nm}$ sized species, the second one to $150-400 \mathrm{~nm}$ sized species and the third one to species with more than $2 \mu \mathrm{m}$. Taking again only the first two (which are much better resolved), the maxima of the peaks corresponded to average hydrodynamic diameters $\left(D_{H}\right)$ of $15.5 \mathrm{~nm}$ (scattering intensity $44.9 \%$ ) and $301.3 \mathrm{~nm}$ (scattering intensity $42.3 \%$ ). The 
A
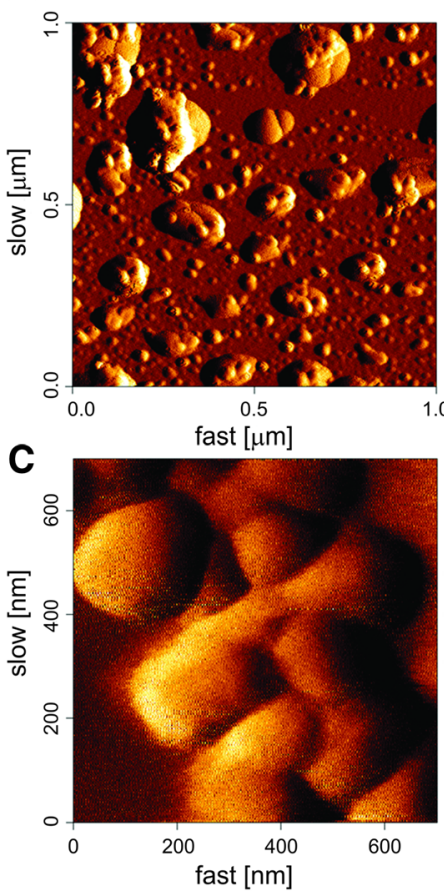

B
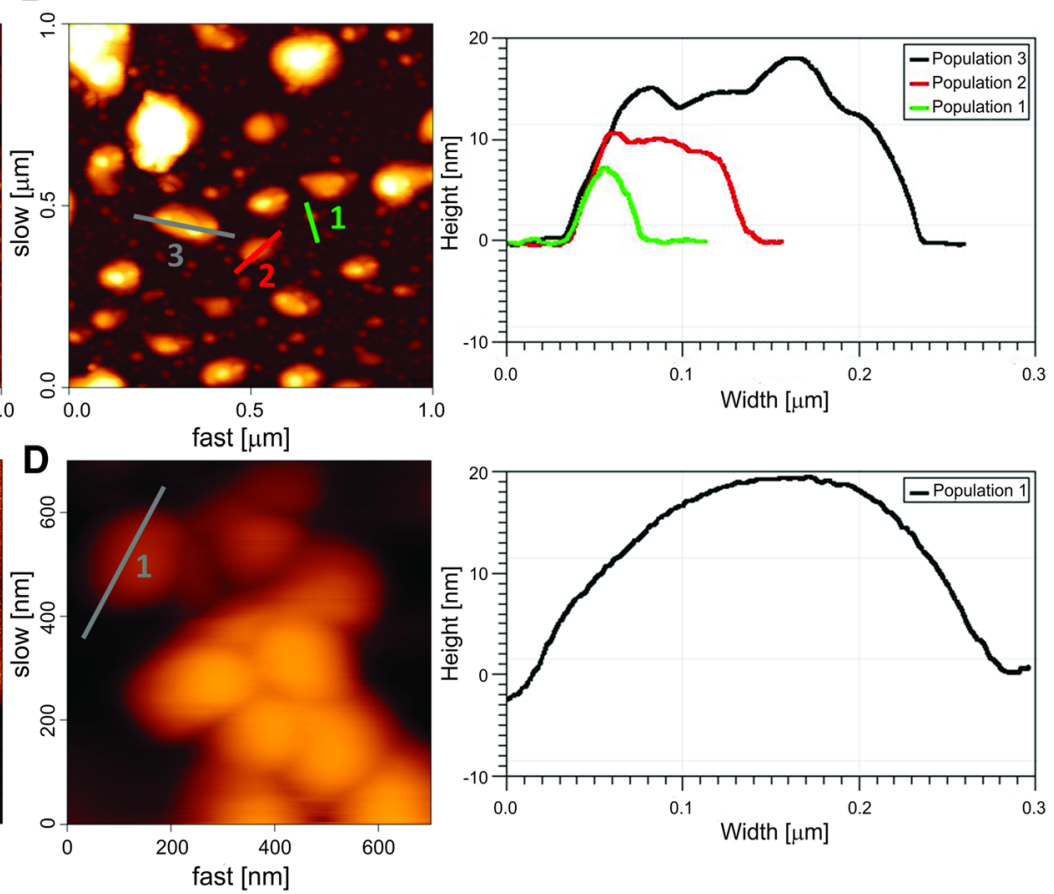

Fig. 2 AFM scanning images of kraft lignin with 1 and 4 days of treatment with $P$. chrysogenum var. halophenolicum. Air tapping mode AFM error (a) and height (b) images of kraft lignin with 1 day of fungal treatment (horizontal scale $1 \mu \mathrm{m} \times 1 \mu \mathrm{m}$; height scale up to $27.6 \mathrm{~nm}$ ). Air contact mode AFM error (c) and height (d) images of kraft lignin with 4 days of fungal treatment (horizontal scale:
$700 \mathrm{~nm} \times 700 \mathrm{~nm}$; height scale up to $66.5 \mathrm{~nm}$ ). Cross section analysis of the AFM height images could also be performed. Three examples of cross sections of the different visualized populations (b right image) and one example of a homogeneous population (d, right image) of the kraft lignin profiles are shown. With this type of analysis, lignin size, height, shape and roughness can be determined

Table 2 Average particles size of fungal treatment samples (hydrodynamic diameter) estimated by dynamic light scattering (DLS)

\begin{tabular}{lllll}
\hline Incubation time $(\mathrm{h})$ & Samples & Peak 1 & Peak 2 & Peak 3 \\
\hline 24 & Fungal treatment & $15.5 \mathrm{~nm}(44.9 \%)$ & $301.3 \mathrm{~nm}(42.3 \%)$ & $3590.0 \mathrm{~nm}(12.8 \%)$ \\
& Control & $16.6 \mathrm{~nm}(34.4 \%)$ & $629.7 \mathrm{~nm}(65.6 \%)$ & No major peak \\
48 & Fungal treatment & $15.2 \mathrm{~nm}(5.0 \%)$ & $191.5 \mathrm{~nm}(80.6 \%)$ & $3551.0 \mathrm{~nm}(12.8 \%)$ \\
& Control & $17.0 \mathrm{~nm}(29.5 \%)$ & $718.4 \mathrm{~nm}(64.0 \%)$ & $4202.0 \mathrm{~nm}(6.5 \%)$ \\
96 & Fungal treatment & No peak & $245.7 \mathrm{~nm}(92.4 \%)$ & $4397.0 \mathrm{~nm}(7.6 \%)$ \\
& Control & $13.0 \mathrm{~nm}(35.3 \%)$ & $250.5 \mathrm{~nm}(43.0 \%)$ & $2053.0 \mathrm{~nm}(21.7 \%)$ \\
\hline
\end{tabular}

Size represents the peak average based on size distribution by volume; the percentages represent the peak area, dark shadowed area highlights homogeneously sized samples (e.g., samples with over $80 \%$ of the particles included within a single size distribution peak)

treatment with $P$. chrysogenum var. halophenolicum appeared to eliminate the larger particles (centered around $629.7 \mathrm{~nm}$ ) resulting in much smaller structures, with about half of the hydrodynamic diameter of the control samples (hydrodynamic diameter centered around $301.3 \mathrm{~nm}$ ). These results support the hypothesis that the fungus had the ability to use differently sized lignin molecules, as described recently by Wang et al. in the lignosulfonate biodegradation process by Sphingobacterium sp. HY-H (Wang et al. 2013). The third peak did not have a good resolution, however, it is clear that the overall scattering particles size decreased, and that also in parallel, the amount of particles with sizes above $1 \mu \mathrm{m}$ is diminished, resulting on an overall extensive reduction and uniformization in particles size.

The same profile was observed after $96 \mathrm{~h}$ of treatment, but in such an extent that the sample can be said to be essentially homogeneous, with one peak at $245.7 \mathrm{~nm}$ (scattering intensity $92.4 \%$ ), with observed reasonable agreement with the AFM data $(321.2 \pm 53.7 \mathrm{~nm})$. A small unresolved peak of particles with more than $1 \mu \mathrm{m}$ was also visible, but with a limited fraction of the intensity. Meanwhile, in the untreated samples three peaks clearly remains after $96 \mathrm{~h}$. These results were consistent with the 
hypothesis that the presence of $P$. chrysogenum var. halophenolicum could promote the polymerization of lignin into well-defined and homogenously sized samples. Overall, and in spite of the small differences between observed AFM and DLS particles size due to the different precision level of the two techniques (DLS size estimation may be distorted by larger particles, while the flattening of the sample to a discoidal shape on the AFM substrate and/or convolution with the AFM tip dimensions also affects size determinations), the results obtained using AFM topographic images were in accordance with those achieved via DLS, showing that not only the low-molecular-weight organic compounds, but also the polycyclic aromatic compounds can be degraded by $P$. chrysogenum var. halophenolicum with the concomitant uniformization of the lignin samples into a single sized species after $96 \mathrm{~h}$ of treatment with the fungus.

\section{Lignin color stability}

As described above, DLS and AFM show that, after $96 \mathrm{~h}$ of fungal treatment, the lignin samples become highly homogenized in terms of size, estimated to be below $390 \mathrm{~nm}$, the approximate lower limit for light detection by the human eye (Starr 2005). This fact prevents, among other phenomena that may interfere with color stability, the occurrence of light scattering phenomena. This can occur in relatively dense solutions, especially, if they form differently sized particles that might eventually modify the color perception. However, in this particular case, light scattering by these uniformly sized lignin particles $(<390 \mathrm{~nm})$ would not be a problem since it would be already in the ultraviolet light spectrum, invisible to the human eye, which helps strengthen the potential of lignin treated samples as color stabilizer. To further evaluate this potential, the lightness values for samples treated with the P. chrysogenum var. halophenolicum after 50 days and 7 months under stability assay conditions, were comparable or slightly higher than the initial $L^{*}$ values (Table 3 ). Moreover, color stability increased after 50 days of

Table 3 Evolution of color difference $\left(\Delta E^{*}\right)$ after 50 days, 7 and 26 months of storage

\begin{tabular}{llll}
\hline Fungal treatment $(\mathrm{h})$ & $\Delta E^{*}$ & & \\
\cline { 2 - 4 } & 50 days/ & 7 months/ & 26 months/ \\
7 days & 7 days & 7 days \\
\hline Control & $0.59 \pm 0.52$ & $1.20 \pm 0.62$ & n.d. \\
24 & $0.55 \pm 0.19$ & $0.90 \pm 0.67$ & $1.06 \pm 0.19$ \\
48 & $0.26 \pm 0.01$ & $0.60 \pm 0.04$ & n.d. \\
96 & $0.17 \pm 0.04$ & $0.61 \pm 0.05$ & $0.68 \pm 0.05$ \\
\hline
\end{tabular}

n.d. not determined storage, since the overall color change $\left(\Delta E^{*}\right)$ values of the samples treated with the fungus were smaller than those of the control samples (Table 3).

For treated fungal samples, the color change for $24 \mathrm{~h}$ was 0.55 . The color change value was 0.17 for $96 \mathrm{~h}$ in the treated fungal samples. These results showed a trace visual change in samples treated more than $48 \mathrm{~h}$ with $P$. chrysogenum var. halophenolicum, according to the scale proposed by Dirckx et al. (Dirckx et al. 1992). Furthermore, the overall color change decreased as fungal contact time increased, suggesting heightened color stability. At the end of 7 months storage, a slight increase of $\Delta E^{*}$ in the treated samples was observed, when compared to the values obtained at 50 days of storage. Nevertheless, in all samples treated with fungus after 7 months of storage, the overall color change was lower than that of the control with 50 days. Furthermore, in the culture treated during $96 \mathrm{~h}$ no significant color change was observed between 7 and 26 months of storage, which is in excellent agreement with the DLS and AFM size estimation showing stable uniform molecules (after fungal treatment). Overall, this strongly supports the hypothesis that the treatment with $P$. chrysogenum var. halophenolicum stabilizes the lignin molecules properties, especially in what regards to color and to its possible use as a color modifies/stabilizer.

\section{Cytotoxicity of kraft lignin before and after fungal treatment}

The evaluation of the potential toxic effects of lignin metabolites was conducted by the determination of the relative proportion of viable cells, by the Alamar Blue ${ }^{\circledR}$ assay. This test is based on the continuous conversion by viable cells of resazurin, a non-fluorescent cell permeable pigment, to resorufin, a fluorescent compound that can be determined by fluorimetric assay, yielding a quantitative measurement of cell survival. We used HeLa cells and human primary skin fibroblasts viability as an indicator of the potential toxic effects of lignin and its metabolites. The $\mathrm{EC}_{50}$ values of kraft lignin showed that it had cytotoxic effects, but only at very high concentrations (Fig. 3). In incubations with fibroblasts, the $\mathrm{EC}_{50}$ for cytotoxicity was higher than HeLa cells $\left(\mathrm{EC}_{50}\right.$ of $5177 \pm 1726$ and $1223 \pm 328 \mathrm{mg} / \mathrm{L}$, respectively in fibroblasts and HeLa cells). At the concentrations of 750, 1000, $2000 \mathrm{mg} / \mathrm{L}$, we observed a significant dose-dependent increment in the HeLa cells viability. A good correlation between the cytotoxic effects on HeLa cells and on fibroblasts cells after $48 \mathrm{~h}$ was observed $(r=0.9775$ and $r=0.9509$, respectively). As it is previously reported the differences between a cancer cell line and primary fibroblasts can be attributed to differences in cell sensitivity to the compound 
Fig. 3 Kraft lignin dose response curves using the Alamar Blue assay. Curves are examples obtained by average of five experimental replicates and illustrate the response of the human primary skin fibroblasts (a) and HeLa cells (b)
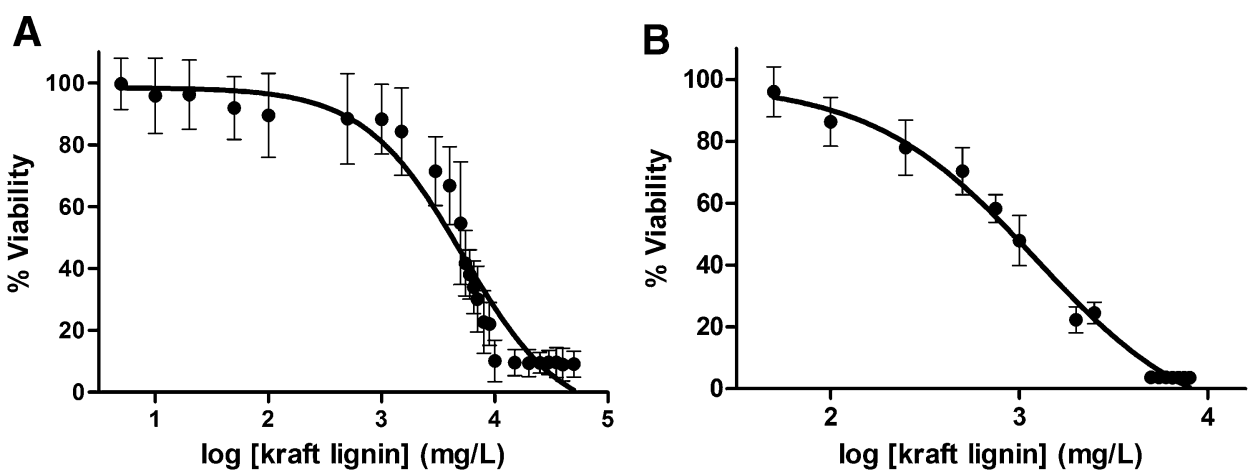

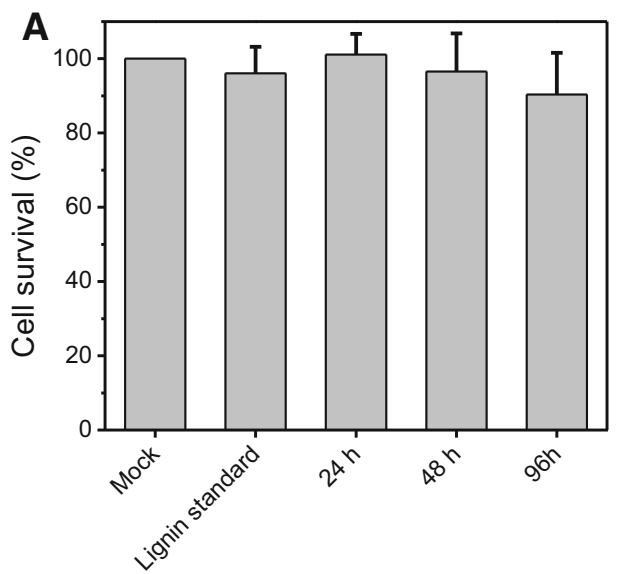

Fig. $4 \mathrm{HeLa}$ and fibroblast cells viability quantified by Alamar Blue assay after incubation with fungal treated and untreated kraft lignin preparations. a HeLa cells, b human primary skin fibroblasts. Mock, untreated cells; Kraft lignin standard, cells incubated with soluble

that is assayed and would be mainly related with the cell division rate (Ugartondo et al. 2008).

To assess if lignin metabolites generated from $P$. chrysogenum var. halophenolicum biological activity are nontoxic for HeLa and fibroblast cells, new experiments were done. The original samples were diluted in cell culture medium before to cytotoxicity testing to obtain a concentration range similar to those where standard lignin concentration begins to be toxic to the tested cells. Results shown in Fig. 4 clearly indicate that both HeLa and fibroblast cells viability were not significantly modified by the exposure to $P$. chrysogenum var. halophenolicum, in comparison with the standard lignin at the same concentrations, indicating that the lignin metabolites generated by P. chrysogenum var. halophenolicum were not cytotoxic.

These results were quite important since it is reported that many dyes are believed to be toxic, some of them as a result of microbial metabolism (Couto 2009). Additionally, Penicillium species are known to produce a high abundance of secondary metabolites including mycotoxins such as ocratoxin A, citrinin, verrucosidin, patulin, among

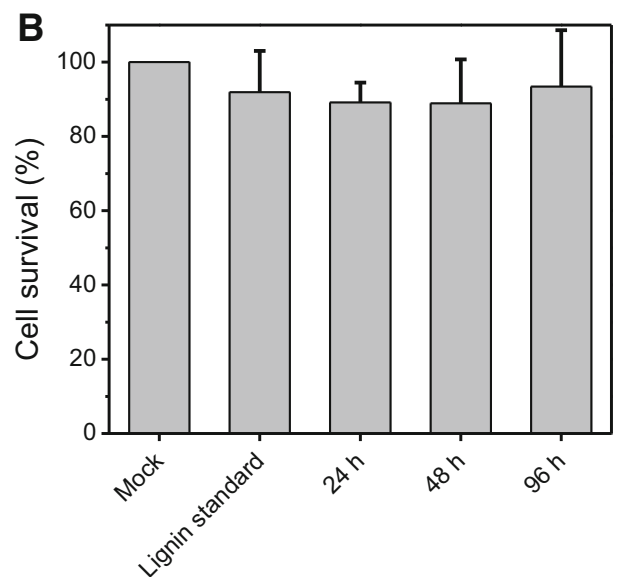

lignin at a concentration of $50 \mathrm{mg} / \mathrm{L} ; 24,48$ and $96 \mathrm{~h}$ represent the time of fungal treatment. Cell survival was calculated as the ratio of fluorescence between sample or standard and mock

others, which have different degrees of toxicity on target organs or are carcinogenic (Chávez et al. 2011). Therefore, it is important to assess the cytotoxic effects of lignin samples after treated with $P$. chrysogenum var. halophenolicum to discard any possible cytotoxic properties.

Despite the potential for biological hazard is low for fungi converted feed as so far, assess cell viability is of major importance to ensure consumer health and safety. The present data indicated that $P$. chrysogenum var. halophenolicum, in this test conditions, did not increase lignin toxicity, showing that kraft lignin can be used over an effective concentration range that is safe for normal and cancer cell lines studied.

The environmental protection agencies are becoming more restrictive regarding water discharge from industrial effluents. Several industries, besides the classical primary and secondary treatments, use physical and chemical tertiary treatments to remove the color cause by lignin and lignin derivatives, which are expensive and not always lead to high performance. Biological technology is a feasible and promising alternative. Fungi have attracted a great deal 
of interest as potential biomass and recalcitrant compounds degraders such as lignin due to their ability to produce a broad diversity of extracellular ligninolytic enzymes some of them with lack specificity for a particular substrate. If white-rot fungi completely mineralize lignin, other fungi and bacteria lead to the production of brown pigments which limits the practical use of such agro residues. Meanwhile, although lignin was generally considered to be nutritionally inert, new scientific data on health-protective mechanisms of cereals endorse the opposite idea (Fardet 2010). Meister advanced a new possible use for modified lignin to pet and human food as roughage, a fiber source, or a cancer protection agent (Meister 2002). Recently, Tortora et al. described the use of kraft lignin as the raw material for microcapsulation processes assembled by ultrasound into lignin microcapsules to storage and release Coumarin6 (Tortora et al. 2014). Several researchers pointed out that a lignin with a more constant structure and size will enhance its potential utilization in high-value products (Norgren and Edlund 2014; Qu et al. 2015).

In summary, this work showed that $P$. chrysogenum var. halophenolicum was able to transform kraft lignin, displaying a higher capacity to grow on lignin substrates. AFM and DLS assays indicated that kraft lignin biotransformation proceeds either via low-molecular phenolic compounds or oligomers. P. chrysogenum var. halophenolicum treatment resulted in a stabilization of commercial soluble kraft lignin color. It is also remarkable that lignin color stability was recorded for more than 24 months at $22{ }^{\circ} \mathrm{C}$ under light conditions of storage. These results were compatible with the hypothesis that $P$. chrysogenum var. halophenolicum could be a potential tool for stabilizing lignin against color change by transforming the heterogeneous lignin composition in a more homogenous structure. The increased lignin stability was achieved without increasing toxicity over HeLa and fibroblast cells. These findings could promote the application of $P$. chrysogenum var. halophenolicum for the development of lignin-fortified formula that would improve food fiber content.

\section{Compliance with ethical standards}

Conflict of interest The authors declare that they have no conflict of interest in the publication.

Open Access This article is distributed under the terms of the Creative Commons Attribution 4.0 International License (http:// creativecommons.org/licenses/by/4.0/), which permits unrestricted use, distribution, and reproduction in any medium, provided you give appropriate credit to the original author(s) and the source, provide a link to the Creative Commons license, and indicate if changes were made.

\section{References}

Al-Nasiry S, Geusens N, Hanssens M, Luyten C, Pijnenborg R (2007) The use of Alamar Blue assay for quantitative analysis of viability, migration and invasion of choriocarcinoma cells. Hum Reprod 22:1304-1309

Baurhoo B, Ruiz-Feria CA, Zhao X (2008) Purified lignin: nutritional and health impacts on farm animals - a review. Anim Feed Sci Technol 144:175-184

Berne BJ, Pecora R (eds) (1990) Dynamic light scattering-with application to chemistry, biology and physic. Krieger Publishing Company, Melbourne

Chakar FS, Ragauskas AJ (2004) Review of current and future softwood kraft lignin process chemistry. Ind Crop Prod 20:131-141

Chandra R, Bharagara RN (2013) Bacterial degradation of synthetic and kraft lignin by axemic and mixed culture and their metabolic products. J Environ Biol 39:991-999

Chávez R, Fierro F, García-Rico RO, Laich F (2011) Mold-fermented foods: Penicillium spp. as ripening agents in the elaboration of cheese and meat products. In: Leitão AL (ed) Mycofactories. Bentham Science Publishers, Sharjah

Chundawat SPS, Donohoe BS, da Costa Sousa L, Elder T, Agarwal UP, Lu F, Ralph J, Himmel ME, Balana V, Daleab BE (2011) Multi-scale visualization and characterization of lignocellulosic plant cell wall deconstruction during thermochemical pretreatment. Energ Environ Sci 4:973-984

Couto SR (2009) Dye removal by immobilised fungi. Biotechnol Adv 27:227-235

DeAngelis MK, Allgaier M, Chavarria Y, Fortney JL, Hugenholtz P, Simmons B, Sublette K, Silver WL, Hazen TC (2011) Characterization of trapped lignin-degrading microbes in tropical forest soil. PLoS One 6:e19306

Dirckx O, Triboulot-trouy MC, Merlin A, Deglixe X (1992) Modifications de la couleur du bois d'Abies grandis exposé à la lumière solaire. Ann Forest Sci 49:425-447

Dwivedi P, Vivekanand V, Pareek N, Sharma A, Singh RP (2011) Cocultivation of mutant Penicillium oxalicum SAU(E)-3.510 and Pleurotus ostreatus for simultaneous biosynthesis of xylanase and laccase under solid-state fermentation. N Biotechnol 28:616-626

El Mansouri N-E, Yuan Q, Huang F (2011) Characterization of alkaline lignins for use in phenol-formaldehyde and epoxy resins. BioResources 6:2647-2662

Fardet A (2010) New hypotheses for the health-protective mechanisms of whole-grain cereals: what is beyond fibre? Nutr Res Rev 23:65-134

George A, Tran K, Morgan TJ, Benke PI, Berrueco C, Lorente E, Wu BC, Keasling JD, Simmonsa BA, Holmes BM (2011) The effect of ionic liquid cation and anion combinations on the macromolecular structure of lignins. Green Chem 13:3375-3385

Guedes SF, Mendes B, Leitão AL (2011) Resorcinol degradation by a Penicillium chrysogenum strain under osmotic stress: mono and binary substrate matrices with phenol. Biodegradation 22:409-419

Gunther K, Schlosser D, Fritsche W (1995) Phenol and cresol metabolism in Bacillus pumilus isolated from contaminated groundwater. J Basic Microbiol 35:83-92

Hao JJ, Tian XJ, Song FQ, He XB, Zhang ZJ, Zhang P (2006) Involvement of lignocellulolytic enzymes in the decomposition of leaf litter in a subtropical forest. J Eukaryot Microbiol 53:193-198 
Huang XF, Santhanam N, Badri DV, Hunter WJ, Manter DK, Decker SR, Vivanco JM, Reardon KF (2013) Isolation and characterization of lignin-degrading bacteria from rainforest soils. Biotechnol Bioeng 110:1616-1626

Janshekar H, Haltmeier T, Brown C (1982) Fungal degradation of pine and straw alkali lignins. Eur J Appl Microbiol 14:174-181

Kadam KL, Drew SW (1986) Study of lignin biotransformation by Aspergillus fumigatus and white-rot fungi using (14)C-labeled and unlabeled kraft lignins. Biotechnol Bioeng 28:394-404

Leitão AL, Duarte MP, Santos Oliveira J (2007) Degradation of phenol by a halotolerant strain of Penicillium chrysogenum. Int Biodeterior Biodegrad 59:220-225

Leitão AL, Garcia-Estrada C, Ullan RV, Guedes SF, Martin-Jimenez P, Mendes B, Martin JF (2012) Penicillium chrysogenum var. halophenolicum, a new halotolerant strain with potential in the remediation of aromatic compounds in high salt environments. Microbiol Res 167:79-89

Lopez-Nicolas JM, Garcia-Carmona F (2007) Use of cyclodextrins as secondary antioxidants to improve the color of fresh pear juice. J Agric Food Chem 55:6330-6338

Lora JH, Glasser WG (2002) Recente industrial applications of lignin: a sustainable alternative to nonrenewable materials. J Polym Environ 10:39-48

Martinez AT, Speranza M, Ruiz-Duenas FJ, Ferreira P, Camarero S, Guillen F, Martinez MJ, Gutierrez A, del Rio JC (2005) Biodegradation of lignocellulosics: microbial, chemical, and enzymatic aspects of the fungal attack of lignin. Int Microbiol $8: 195-204$

Meister JJ (2002) Modification of lignin. J Macromol Sci Polymer Rev C42:235-289

Norgren M, Edlund H (2014) Lignin: recent advances and emerging applications. Curr Opin Colloid Interface Sci 19:409-416

Pérez J, Moraleda-Muñoz A (2011) Fungal lignocellulolytic enzymes: applications in biodegradation and bioconversion. In: Leitão $\mathrm{AL}$ (ed) Mycofactories. Bentham Scientific Publishers, Sharjah

Polman JK, Stoner DL, Delezene-Briggs KM (1994) Bioconversion of coal, lignin, and dimethoxybenzyl alcohol by Penicillium citrinum. J Ind Microbiol 13:292-299

Provencher SW (1982a) Constrained regularization method for inverting data represented by linear algebraic or integralequations. Comput Phys Commun 27:213-227
Provencher SW (1982b) Contin—a general-purpose constrained regularization program for inverting noisy linear algebraic and integral-equations. Comput Phys Commun 27:229-242

Qu Y, Luo H, Li H, Xu J (2015) Comparison on structural modification of industrial lignin by wet ball milling and ionic liquid pretreatment. Biotechnol Rep 6:1-7

Rodriguez A, Carnicero A, Perestelo F, de la Fuente G, Milstein O, Falcon MA (1994) Effect of Penicillium chrysogenum on Lignin transformation. Appl Environ Microbiol 60:2971-2976

Rodriguez A, Falcon MA, Carnicero A, Perestelo F, De la Fuente G, Trojanowski J (1996) Laccase activities of Penicillium chrysogenum in relation to lignin degradation. Appl Microbiol Biotechnol 45:399-403

Starr C (2005) Biology: concepts and applications, 6th edn. Thomson Brooks/Cole, USA

Suparno O, Covington AD, Evans CS (2005) Kraft lignin degradation products for tanning and dyeing of leather. J Chem Technol Biotechnol 80:44-49

Tortora M, Cavalieri F, Mosesso P, Ciaffardini F, Melone F, Crestini C (2014) Ultrasound driven assembly of lignin into microcapsules for storage and delivery of hydrophobic molecules. Biomacromolecules 15:1634-1643

Ugartondo V, Mitjans M, Vinardell MP (2008) Comparative antioxidant and cytotoxic effects of lignins from different sources. Bioresour Technol 99:6683-6687

Walker JRL (1977) Enzymatic browning in foods. Food Technol 12:19-25

Wang D, Lin Y, Du W, Liang J, Ning Y (2013) Optimization and characterization of lignosulfonate biodegradation process by a bacterial strain, Sphingobacterium sp. HY-H. Int Biodeterior Biodegrad 85:365-371

Wong DW (2009) Structure and action mechanism of ligninolytic enzymes. Appl Biochem Biotechnol 157:174-209

Yadav M, Yadav KD (2006) Enzymatic characteristics of ligninperoxidases from Penicillium citrinum, Fusarium oxysporum and Aspergillus terreus using $\mathrm{n}$-propanol as substrate. Indian $\mathrm{J}$ Biochem Biophys 43:48-51

Yuan Z, Cheng S, Leitch M, Xu CC (2010) Hydrolytic degradation of alkaline lignin in hot-compressed water and ethanol. Bioresour Technol 101:9308-9313 